\title{
CARACTERIZAÇÃO E GÊNESE DE PERFIS PLÍNTICOS DESENVOLVIDOS DE ARENITO DO GRUPO BAURU. I - QUÍ MICA(1)
}

\author{
M. R. COELHO(2) \& P. VIDAL-TORRADO(3)
}

\begin{abstract}
RESUMO
Plintita e petroplintita são feições de ocorrência comum nos solos desenvolvidos de arenitos do Grupo Bauru, Formação Adamantina, nas regiões norte e oeste do estado de São Paulo. Com o objetivo de avaliar os atributos químicos, bem como os processos pedogenéticos envolvidos na formação desses materiais e dos perfis onde ocorrem, foram estudados dois solos da baixa meia encosta de uma vertente representativa da paisagem local, constituída por feições plínticas, petroplínticas e mosqueados. O estudo foi realizado na Estação Experimental de Agronomia de Pindorama do Instituto Agronômico de Campinas (IAC), região norte do estado de São Paulo. Com base nas análises pedológicas de rotina, dissoluções seletivas e fluorescência de raios-X, constatou-se a origem predominantemente oxídica das glébulas estudadas, não associadas a compostos orgânicos, com baixos teores de manganês e maiores conteúdos de ferro pouco cristalino nas plintitas, comparativamente às petroplintitas. A segregação e preci pi tação de ferro em massa, os mecanismos de eluviação-iluviação das argi las e compostos de ferro, a ferrólise, bem como a degradação dos horizontes petroplínticos, liberando ferro para a formação da plintitas sotopostas, correspondem aos principais processos pedogenéticos atuantes nos perfis estudados, os quais influenciam sobremaneira os atributos químicos dos horizontes saprolíticos dos perfis plínticos.
\end{abstract}

Termos de indexação: plintita, petroplintita, dissoluções seletivas, fluorescência de raios-X.

(1) Parte da Tese de Mestrado apresentada, pelo primeiro autor, ao curso de Pós-Graduação em Solos e Nutrição de Plantas da Escola Superior de Agricultura "Luiz de Queiroz" - ESALQ/USP. Recebido para publicação em abril de 2002 e aprovado em março de 2003.

(2) Pesquisador do Centro Nacional de Pesquisa em Solos, E mbrapa Solos. Rua J ardim Botânico 1024, J ardim Botânico, CEP 22460 000 Rio de J aneiro (RJ ). E-mail: mrcoelho@cnps.embrapa.br

(3) Professor do Departamento de Ciência do Solo, Escola Superior de Agricultura "Luiz de Queiroz" - ESALQ/USP. Caixa Postal 09, CEP 13.418-900 Piracicaba (SP). Bolsista do CNPq. E-mail: pablo@carpa.ciagri.usp.br 


\title{
SUMMARY: CHARACTERIZATION AND GENESIS OF PLINTHIC PROFILES DEVELOPED ON SANDSTONE (BAURU GROUP). I - CHEMICAL PROPERTIES
}

\begin{abstract}
Plinthite and petroplinthite are commonly present features in soils developed on sandstoneof theBauru Group, Adamantina Formation, in thenorthern and western region of São Paul o State. Theobjective of this study was to evaluatechemical properties as well as pedogenic processes that led to the formation of these materials and the soil profile. Two soils at the foot of a representative mountainside of the local landscape with plinthic, petroplinthic and mottling features weresel ected within areas of the Experimental Station Pindorama of the Agronomic Institute Campinas (IAC), in the N orth of São Paulo State. Based on pedological routine analyses, selective dissolution, and X-ray fluorescence, the predominantly oxidic origin of the glaebules was diagnosed. These gleabules are not associated with organic compounds, contain low amounts of manganese, and higher levels of poor crystal lineiron in theplinthites than in thepetropl inthites. Main pedogenic processes that affected chemical characteristics of the saprolitic horizons in the studied profiles are: segregation and precipitation of high amounts of iron; mechanisms of eluviation-iluviation of clay and iron compounds, theferrolysis; degradation of thepetropl inthichorizons re easing iron to originate underlying plinthite.
\end{abstract}

Index terms: plinthite, petroplinthite, selective dissol ution, X-ray fluorescence

\section{INTRODUÇÃO}

Materiais ricos em ferro, tais como: horizontes litoplínticos (EMBRAPA, 1999) eferricretes, quesão duros ou cimentados (Bourman, 1993), apresentam ampla variabilidade de características químicas, morfológicas e mineralógicas (Alexander \& Cady, 1962; Sivarajasingham et al., 1962), relacionada com a idade, grau de evolução e natureza da rocha de origem dos quais eles derivam (I banga, 1980; Roquin et al., 1990). No entanto, uma característica comum desses materiais é seu el evado conteúdo de ferro e, ou, alumínio, quando comparadoa outros constituintes (Sivarajasingham et al., 1962). Considerando apenas o ferro, seus teores excepcionalmente atingem $75 \mathrm{~g} \mathrm{~kg}^{-1} \mathrm{deF}_{2} \mathrm{O}_{3}$, mas, geralmente, variam de 400 a $650 \mathrm{~g} \mathrm{~kg}^{-1}$ (Tardy, 1993).

Embora os elementos ferro, alumínio e silício sejam os mais abundantes constituintes dessas feições ferruginosas, muitos outros estão freqüentemente associados, porém em menores proporções (Roquin, et al., 1990). Titânio, por exemplo, pode mesmo atingir proporções significativas (Sivarajasingham et al., 1962) e, em geral, representa uma acumulação relativa do material parental (I banga, 1980). O manganês pode ocorrer sob várias formas, predominantemente amorfas (McKenzie, 1989), muitas vezes constituindo o principal elemento de nódul os e concr eções enegreci das e concentra-se nas glébulas ferruginosas, seja na forma de "coatings", seja na de veios ou manchas pretas (Taylor \& MacKenzie, 1966).

Apesar de pouco documentadas, a petroplintita e a plintita ocorrem de forma freqüente nos solos derivados da Formação Adamantina, regiões norte e oeste do estado de São Paulo, onde, muitas vezes, ocorrem perfis completamente dominados por essas feições. Apresentam-se com diferentes padrões morfológicos, quantidade de material nodular, espessura dos horizontes (petroplíntico e plíntico), profundidade de ocorrência, classes e atributos dos solos onde ocorrem e posição que ocupam na paisagem (Coel ho et al., 2001). Os trabal hos que avaliam a constituição desses materiais, além de sua caracterização como constituinte do regolito, possibilitam um melhor entendimento da evolução dos sistemas de intemperismo e, com isso, fornecem informações imprescindíveis ao estudo dos mecanismos envol vidos na sua gênese, principalmente quando uma filiação é estabelecida entre os diferentes horizontes dos perfis estudados.

O presente trabalho objetiva caracterizar quimicamente as diferentes feições ferruginosas e os perfis onde ocorrem, bem como utilizar o comportamento dos el ementos quími cos identificados a fim de proporcionar o entendimento de alguns mecanismos envolvidos na gênese dos perfis plínticos. Para tanto, foram sel ecionados dois perfis de solos desenvolvidos dos arenitos cretácicos da Formação Adamantina do Grupo Bauru, e localizados na baixa meia encosta de uma vertente representativa da paisagem local, dominada por feições plínticas, petroplínticas e mosqueados.

\section{MATERIAL E MÉTODOS}

\section{Meio físico}

O estudo foi realizado na Estação Experimental deAgronomia de Pindorama do InstitutoAgronômico 
(IAC), situada ao sul do município de Pindorama, nas coordenadas geográficas $21^{\circ} 13^{\prime}$ 'de latitudesul e $48^{\circ} 56$ ' de longitude oeste. De acordo com o mapa geológico do estado de São Paulo (IPT, 1981), a Estação local iza-se na região sob domínio do Grupo Bauru, Formação Adamantina, caracterizada por apresentar bancos de arenitos com granulação fina a muito fina, alternados com lamitos, siltitos e arenitos lamíticos, sendo comum a ocorrência de seixos de argilito, cimento e de nódul os carbonáticos (Soares et al., 1980).

O clima da região enquadra-senotipo $A w$, segundo a classificação de Köppen, definido como tropical úmido com estação chuvosa no verão e seca no inverno, com preci pitação média anual de $1.390 \mathrm{~mm}$.

\section{Trabalho de campo}

Consistiu na sel eção do segmento de vertente que melhor caracterizava as diferentes classes de solos com ocorrência expressiva e representativa das feições ferruginosas. Conhecido o segmento, foram abertas duas trincheiras. A localização dessas, a classificação ea morfol ogia detalhada dos solos, bem como a distribuição lateral e vertical dos horizontes e camadas do segmento estudado, são apresentadas por Coel ho et al. (2001). Noentanto, oquadro 1 mostra a classificação e alguns dos principais atributos morfológicos referentes aos perfis estudados.

\section{Análises laboratoriais}

No laboratório, as amostras de solo foram secas ao ar, destorroadas com um martelo de borracha e passadas em peneira $\mathrm{n}$ o 10 (mal ha de $2 \mathrm{~mm}$ ), obtendo a fração terra fina seca ao ar (TFSA), onde foram realizadas as análises granulométricas e químicas.

As amostras provenientes dos horizontes plínticos e petroplínticos foram submetidas ao peneiramento por via úmida em peneira № 10 para separar os

\section{Quadro 1. Classi ficação e morfologia dos perfis estudados}

Horizonte Profundidade Cor úmida Textura Consistência

\section{$\mathrm{m}$}

Perfil P1 - Plintossolo Pétrico Concrecionário distrófico típico, textura arenosa/média esquelética, A moderado(1)

\begin{tabular}{|c|c|c|c|c|c|}
\hline A & $0,00-0,10$ & 7,5 YR 4/2 & Areia franca & $\begin{array}{l}\text { Moder ada, pequena e média } \\
\text { blocos subangulares }\end{array}$ & $\begin{array}{l}\text { Macia, muito friável, não } \\
\text { plástica e não pegajosa }\end{array}$ \\
\hline$E$ & $0,10-0,25$ & 7,5 YR $4 / 4$ & Areia franca & $\begin{array}{l}\text { Fraca, média e grande, blocos } \\
\text { subangulares }\end{array}$ & $\begin{array}{l}\text { Ligeiramente dura, friável, não } \\
\text { plástica e não pegajosa }\end{array}$ \\
\hline $\mathrm{Cc}$ & $0,25-0,45$ & 5 YR 4/6 & $\begin{array}{l}\text { Franco-argilo- } \\
\text { arenosa }\end{array}$ & Matriz interglebular maciça & Plástica e pegajosa \\
\hline $\mathrm{Cf}$ & $0,45-0,55$ & 5 YR 4/6 & $\begin{array}{l}\text { Franco-argilo- } \\
\text { arenosa }\end{array}$ & Matriz interglebular maciça & Plástica e pegajosa \\
\hline $\mathrm{Cr}$ & $0,55-1,16$ & 2,5 YR $4 / 8$ & $\begin{array}{l}\text { Franco-argilo- } \\
\text { arenosa }\end{array}$ & $\begin{array}{l}\text { Fragmentos de rocha } \\
\text { entremeados a uma matriz } \\
\text { terrosa maciça }\end{array}$ & $\begin{array}{l}\text { Dura, muito firme, plástica e } \\
\text { pegajosa }\end{array}$ \\
\hline Crg1 & $1,16-1,40$ & Variegada & $\begin{array}{l}\text { Franco-argilo- } \\
\text { arenosa }\end{array}$ & $\begin{array}{l}\text { Fragmentos de rocha } \\
\text { entremeados a uma matriz } \\
\text { terrosa maciça }\end{array}$ & $\begin{array}{l}\text { Ligeiramente dura, firme, } \\
\text { plástica e pegajosa }\end{array}$ \\
\hline Crg2 & $1,40-1,80$ & Variegada & Areia franca & $\begin{array}{l}\text { Fragmentos de rocha } \\
\text { entremeados a uma matriz } \\
\text { terrosa maciça }\end{array}$ & $\begin{array}{l}\text { Ligeiramente dura, firme, } \\
\text { ligeiramente plástica e } \\
\text { ligeiramente pegajosa }\end{array}$ \\
\hline
\end{tabular}

Perfil P2 - Argissolo Vermelho-Amarelo Eutrófico abrúptico plíntico, textura arenosa/média, A moderado

\begin{tabular}{|c|c|c|c|c|c|}
\hline A & $0,00-0,10$ & 7,5 YR 4/2 & Areia franca & $\begin{array}{l}\text { Fraca, média, blocos } \\
\text { subangulares }\end{array}$ & $\begin{array}{l}\text { Macia, friável, não-plástica e } \\
\text { não-pegajosa }\end{array}$ \\
\hline$E$ & $0,10-0,26$ & 7,5 YR 4/4 & Areia franca & $\begin{array}{l}\text { Fraca, média, blocos } \\
\text { subangulares }\end{array}$ & $\begin{array}{l}\text { Ligeiramente dura, friável, } \\
\text { não-plástica e não-pegajosa }\end{array}$ \\
\hline Bt1 & $0,26-0,38$ & 5 YR 4/6 & $\begin{array}{l}\text { Franco-argilo- } \\
\text { arenosa }\end{array}$ & $\begin{array}{l}\text { Moderada, média e grande, } \\
\text { blocos subangulares }\end{array}$ & $\begin{array}{l}\text { Dura, firme, ligeiramente } \\
\text { plástica e ligeiramente } \\
\text { pegajosa }\end{array}$ \\
\hline Bt2 & $0,38-0,60$ & 5 YR 4/8 & $\begin{array}{l}\text { Franco-argilo- } \\
\text { arenosa }\end{array}$ & $\begin{array}{l}\text { Moder ada, média e grande, } \\
\text { blocos subangulares }\end{array}$ & $\begin{array}{l}\text { Dura, firme, plástica e } \\
\text { pegajosa }\end{array}$ \\
\hline $\mathrm{Cc}$ & $0,60-0,85$ & 5 YR 4/6 & $\begin{array}{l}\text { Franco-argilo } \\
\text { arenosa muito } \\
\text { cascalhenta }\end{array}$ & Matriz maciça & Plástica e pegajosa \\
\hline$C f$ & $0,85-1,10$ & 5 YR 4/8 & $\begin{array}{l}\text { Franco-argilo- } \\
\text { arenosa muito } \\
\text { cascalhenta }\end{array}$ & Matriz maciça & Plástica e pegajosa \\
\hline $\mathrm{Cr}$ & $1,10-1,64$ & 2,5YR 4/6 & $\begin{array}{l}\text { Franco-argilo- } \\
\text { arenosa }\end{array}$ & $\begin{array}{l}\text { Estrutura original da rocha } \\
\text { entremeada a uma matriz } \\
\text { terrosa maciça }\end{array}$ & $\begin{array}{l}\text { Ligeiramente dura, firme, } \\
\text { plastica pegajosa }\end{array}$ \\
\hline $\mathrm{R}$ & $1,64-1,90$ & $2,5 Y R \quad 4 / 6$ & Franco-arenosa & Estrutura da rocha & $\begin{array}{l}\text { Dura, firme, ligeiramente } \\
\text { plástica e ligeiramente } \\
\text { pegajosa }\end{array}$ \\
\hline
\end{tabular}


nódul os da matriz interglebular. Posteriormente, os nódulos foram individualmente escovados em água corrente, secos ao ar, triturados em moinho mecânico e passados em peneira no 10 . O solo dos horizontes plínticos e petroplínticos (matriz interglebular) foram secos ao ar, sendo parte destinado à determinação granulométrica e parte às determinações químicas. Apenas o horizonte plíntico do perfil P2 foi submetido aos procedimentos convencionais de preparo das amostras, ou seja, os nódulos e a matriz foram homogeneizados com martel o de borracha e passados em peneira.

\section{Análises químicas de rotina}

Essas determinações seguiram os métodos recomendados por Raij et al. (1987).

\section{Dissoluções seletivas}

As determinações deferro, alumínio e manganês livres e amorfos foram feitas segundo o "Manual for Soil and Water Analysis", editado por Buurman et al. (1996). As formas livres foram extraídas após redução dos el ementos em meio tampão de citrato e ditionito (DC). As formas amorfas foram extraídas em solução ácida de oxal ato, após agitação no escuro durante quatro horas. Para as determinações de ferro e manganês facilmente redutíveis, utilizou-se o método da Hidroxilamina proposto por Gambrell (1996). Todos os el ementos foram medidos em espectrofotômetro de absorção atômica.

\section{Ataque sulfúrico}

Para obter os elementos com ataque sulfúrico utilizou-se o método preconizado por Vettori (1969), com algumas modificações propostas por Raij \& Valadares (1974).

\section{Fluorescência de raios-X}

Os teores de silício, alumínio, titânio, ferro e manganês totais foram determinados por fluorescênda deraios-X em aparel ho Philips, model o PW 2400.

\section{Análises estatísticas}

Os graus de relacionamento entre os teores dos el ementos obtidos por ataquesulfúrico efluorescência de raios-X foram avaliados pela anál ise de correlação e teste de Student (t) para dados pareados.

\section{RESULTADOS E DISCUSSÃO}

\section{Análises químicas de rotina}

Os resultados analíticos de rotina para os perfis estudados são apresentados no quadro 2. De sua análise observa-se que as glébulas dos horizontes petroplínticos apresentaram os menores conteúdos de matéria orgânica dentre todas as amostras analisadas, evidenciando sua origem dissociada deste componente.

Quadro 2. Análises químicas dos perfis P1 e P2

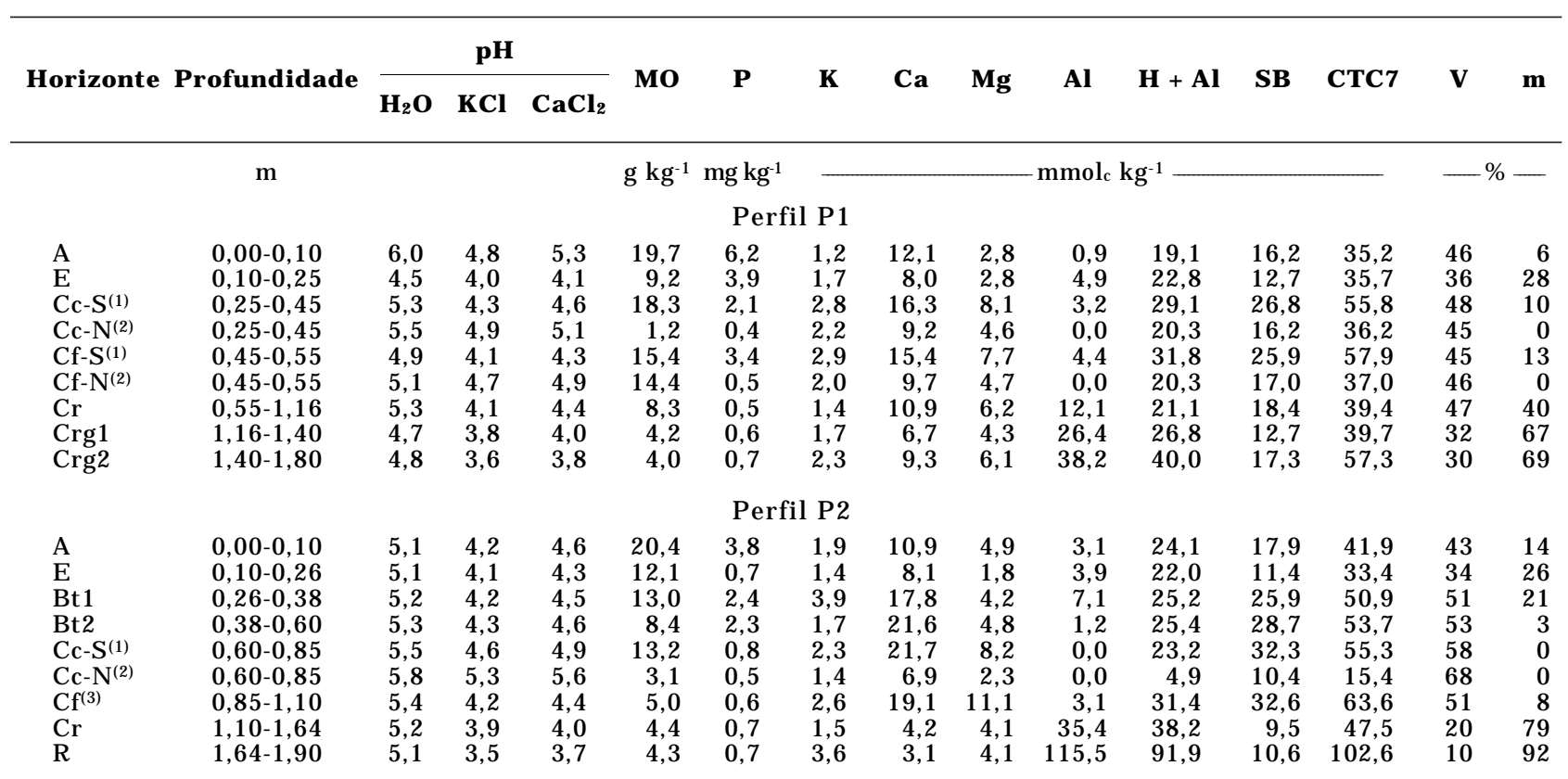

(1) Cc-S e Cf-S: matriz interglebular dos horizontes petroplíntico (Cc) e plíntico (Cf) respectivamente. ${ }^{(2)}$ Cc-N e Cf-N : nódulos dos horizontes Cc e Cf respectivamente. ${ }^{(3)} \mathrm{Cf}$ : horizonte Cf do perfil P2. Amostra homogeneizada (nódulos + matriz). 
A reação do solo manteve-se ligeiramente ácida em todos os horizontes dos perfis estudados. Os menores valores são observados nos horizontes e camada inferiores, principalmente na camada $\mathrm{R}$ do perfil P2. Nesta, os baixos valores de $\mathrm{pH}$ em $\mathrm{KCl}$ $(3,5)$ e $\mathrm{CaCl}_{2}(3,7)$ registrados estão relacionados com o el evado conteúdo de alumínio $\left(115,2 \mathrm{mmol}_{\mathrm{C}} \mathrm{kg}^{-1}\right)$, como confirmado nas determinações do el emento e acidez potencial.

Associados às variações de $\mathrm{pH}$, os menores conteúdos de cátions básicos trocáveis (SB) e saturação por bases (V) foram verificados nos horizontes Crg1 e Crg2 do perfil P1, bem como no horizonte $\mathrm{Cr}$ e camada $\mathrm{R}$ do perfil $\mathrm{P} 2$, os quais apresentam grande parte de sua CTC ocupada com alumínio trocável, possivelmente relacionados com o mecanismo de ferrólise, conforme indicações de Brinkman (1970). Segundo o autor, esse mecanismo é pronunciado nos solos ácidos sujeitos à redução sazonal. Os perfis estudados permanecem boa parte do período chuvoso com seus horizontes inferiores saturados e mostram uma acentuada oscilação no nível de água, tal como evidenciado nos trabalhos de campo. Além disso, apresentam um conteúdo substancial de ferro (Quadros 3 e 4), possivel mente boa parte dele decorrente de sua mobilização do horizonte $\mathrm{F}$ e deposição nos horizontes inferiores, satisfazendo a exigência da presença do elemento no desenvolvimento da ferrólise.

Assim, esse mecanismo é atuante em todos os perfis estudados, desestruturando eliberando Al da estrutura dos minerais silicatados, os quais ficam livres para ocupar os sítios de troca das argilas ou serem incorporados nas estruturas dos óxidos e hidróxidos de ferro secundários durante a evolução dos solos na paisagem. É mais pronunciado nos horizontes inferiores do perfil P2, não só pelo el evado conteúdo de ferro em relação aos demais horizontes ondea ferrólise éativa, mas também pelas condições químicas que desfavorecem a formação de gibbsita secundária, possivel mente pel o el evado conteú do de sílica presente (Anjos et al., 1995) (Quadro 3).

Com relação aos nódulos dos horizontes, estes mostram baixos valores de SB e CTC7 (Quadro 2), com seus menores conteúdos verificados nas petroplintitas (Cc-N) do perfil P2. A mineralogia predominantementeoxídica, a elevada cristal inidade dos óxidos e hidróxidos de ferro e o intenso processo detransformações predominantementedesgastantes que se processam durante a gênesee evolução desses materiais são responsáveis por esses resultados.

Quadro 3. Valores de Ki, Kr e teores de silício, alumínio, ferro, manganês e titânio obtidos por ataque sulfúrico e fluorescência de raios-X

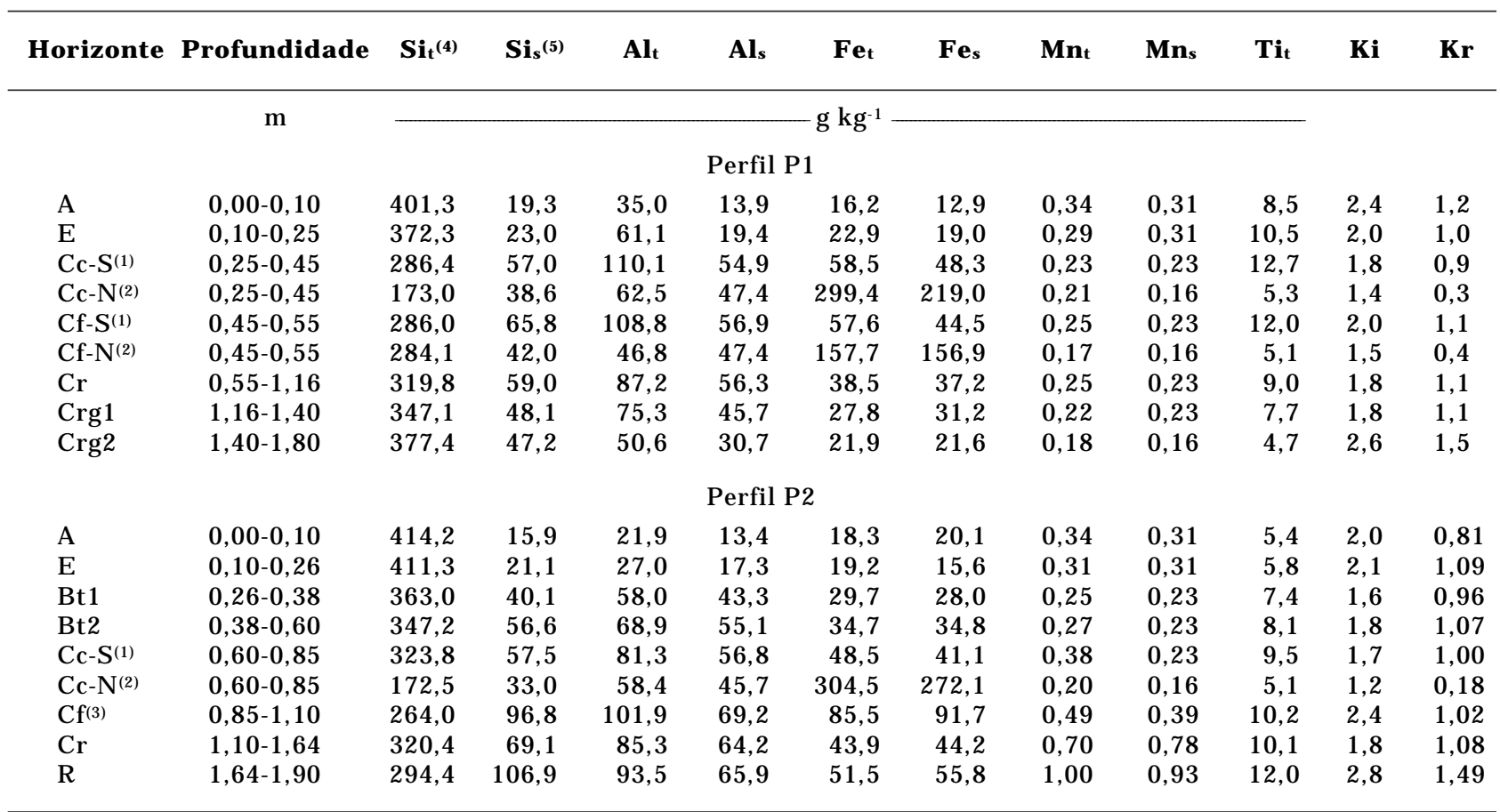

(1) Cc-S e Cf-S: matriz interglebular dos horizontes petroplíntico (Cc) e plíntico (Cf), respectivamente. (2) Cc-N e Cf-N : nódulos dos horizontes C e Cf, respectivamente. ${ }^{(3)} \mathrm{Cf}$ : horizonte Cf do perfil P2. Amostra homogeneizada (nódulos + matriz). ${ }^{(4)}$ subscrito s: elemento obtido por ataque sulfúrico. ${ }^{(5)}$ subscrito t: elemento obtido por fluorescência de raios-X. 
Quadro 4. Teores de ferro (F e), alumínio (Al) e manganês (Mn) determi nados por ditionito-citrato, oxalato e hidroxilamina

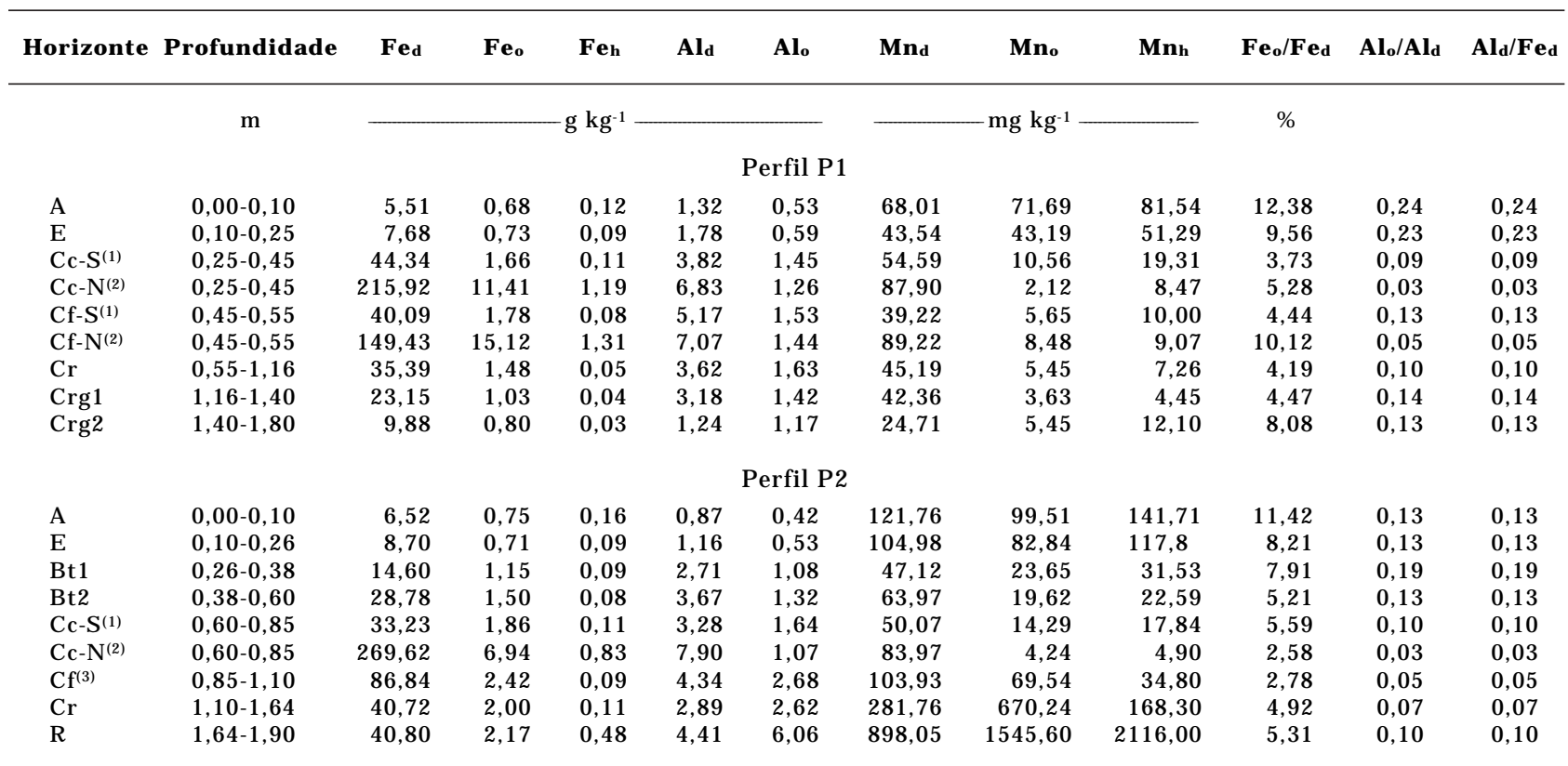

${ }^{(1)}$ Cc-S e Cf-S: matriz interglebular dos horizontes petroplíntico (Cc) e plíntico (Cf), respectivamente. ${ }^{(2)}$ Cc-N e Cf-N : nódulos dos horizontes Cc e Cf, respectivamente. ${ }^{(3)} \mathrm{Cf}$ : horizonte Cf do perfil P2. Amostra homogeneizada (nódulos + matriz). Subscritos: d ditionito; o - oxalato; h - hidroxilamina.

\section{Ataque sulfúrico e fluorescência de raios-X}

Os conteúdos de silício, alumínio, ferro, manganêse titânio extraídos dos solos e nódulos estudados encontram-se no quadro 3. Os nódul os mostram os maiores conteúdos de ferro, com valores totais variando de $304,5 \mathrm{~g} \mathrm{~kg}^{-1}$, na petroplintita (perfil P2), a $157,7 \mathrm{~g} \mathrm{~kg}^{-1}$, na plintita (perfil P1), enquanto os teores de $\mathrm{Si}_{\mathrm{t}} \mathrm{eTi}_{\mathrm{t}}$ correspondem aos menores dentre todas as amostras analisadas (Quadro 3). São de constituição predominantemente oxídica, como pode ser evidenciado pel os baixos val ores de $\mathrm{Ki}(\mathrm{Ki}<1,39)$ e $\mathrm{Kr}(\mathrm{Kr}<0,75)$.

A relação entre os teores de ferro extraídos por ataque sulfúrico e fluorescência de raios-X é mostrada na figura 1 , permitindo uma análise comparativa entre duas diferentes formas de extração. Observa-se que não há diferença significativa entre os métodos utilizados, corroborada tanto pel o teste de Student (t) a $1 \%$ de probabilidade, como pelo coeficiente de correlação (r). O perfeito relacionamento e o ótimo grau de concordância entre os diferentes métodos seriam representados pelos pontos sobre a reta com inclinação de $45^{\circ}$ e que passa pela origem. Nota-se também que os pontos que mais se afastam da reta correspondem às amostras petroplínticas dos perfis estudados, sugerindo que o el evado teor e, ou, grau de cristal inidade dos óxidos de ferro são fatores que interferem na extração do Fe por ataque sulfúrico, uma vez que essas amostras correspondem àquelas com maior conteúdo do elemento dentre todas as analisadas (Quadro 3) e com o maior grau de cristalinidade dos óxidos, tal como evidenciado pela baixa relação $\mathrm{Fe}_{d} / \mathrm{Fe}_{\mathrm{d}}$ (Quadro 4).

O conteúdo de manganês $(\mathrm{Mn})$ é baixo em todas as amostras analisadas. Os menores valores são

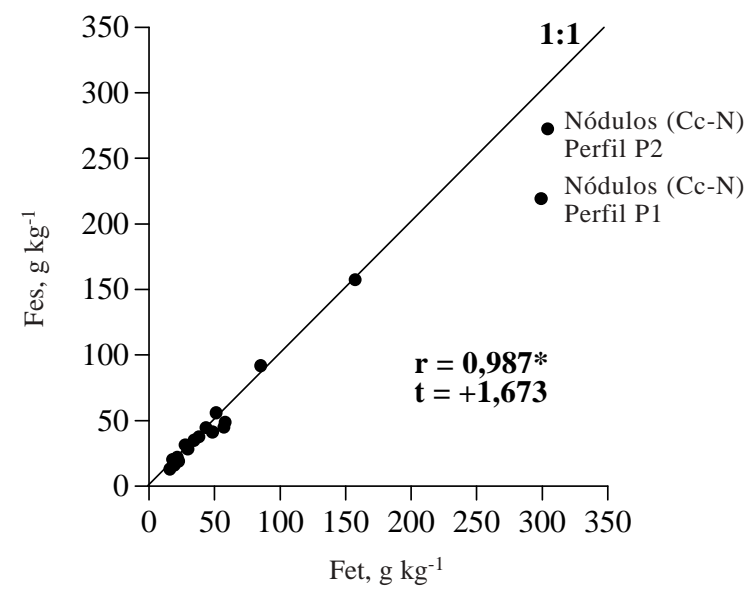

Figura 1. Relação entre os teores de ferro obtidos por ataque sulfúrico $\left(\mathrm{Fe}_{\mathrm{s}}\right)$ e fluorescência de raios-X $\left(F e_{t}\right)$. A reta corresponde a uma inclinação de $45^{\circ}$, passando pela origem. 
encontrados nas glébulas plínticas e petroplínticas dos perfis estudados (Quadro 3). No entanto, a maior concentração do el emento é verificada no horizonte $\mathrm{Cr}\left(\mathrm{Mn}_{\mathrm{t}}=0,70 \mathrm{~g} \mathrm{~kg}^{-1}\right)$ e camada $\mathrm{R}\left(\mathrm{Mn}_{\mathrm{t}}=1,00 \mathrm{~g} \mathrm{~kg}^{-1}\right)$ do perfil P2 como resultado das condições hidrológicas atuais da seqüência estudada, favorecendo potenciais de oxirredução adequados à precipitação de óxidos de manganês na superfície dos fragmentos de saprolito e fendas da rocha, tal como observado na morfologia de campo.

Resultados semelhantes aos descritos para o elemento ferro podem ser considerados para o manganês, quando se observa a similaridade entre os teores obtidos por fluorescência de raios- $X$ e ataque sulfúrico. A figura 2 evidencia que, para as amostras analisadas, não há diferença significativa a $1 \%$ entre os teores de $\mathrm{Mn}$ determinados pelos diferentes métodos, embora os valores obtidos por fluorescência de raios- $X\left(M n_{t}\right)$ sejam, em sua maioria, superiores aos obtidos por ataquesulfúrico $\left(\mathrm{Mn}_{\mathrm{s}}\right)$.

\section{Dissoluções seletivas}

A distribuição, em profundidade, dos conteúdos deferro obtidos por ataque sulfúrico $\left(\mathrm{Fe}_{\mathrm{s}}\right)$ e ditionito de sódio é mostrada na figura 3 . Considerando que hematita e goethita foram os únicos óxidos de ferro identificados nas análises mineralógicas (Coel ho \& Vidal-Torrado, 2003), pode-seargumentar que o $\mathrm{Fe}_{\mathrm{d}}$ equivale ao ferro extraído desses minerais, uma vez quea fração amorfa $\left(\mathrm{Fe}_{\mathrm{o}}\right)$ é pouco expressiva. Sendo assim, tanto e principalmente os nódul os (Quadro 4), como a matriz intergl ebular eos horizontes $\mathrm{Cr}$ abaixo dos horizontes plínticos (perfis P1 e P2), mostramse com o ferro predominantemente nas formas oxídicas e cristalinas. No entanto, nota-se um distanciamento entre as curvas nos horizontes

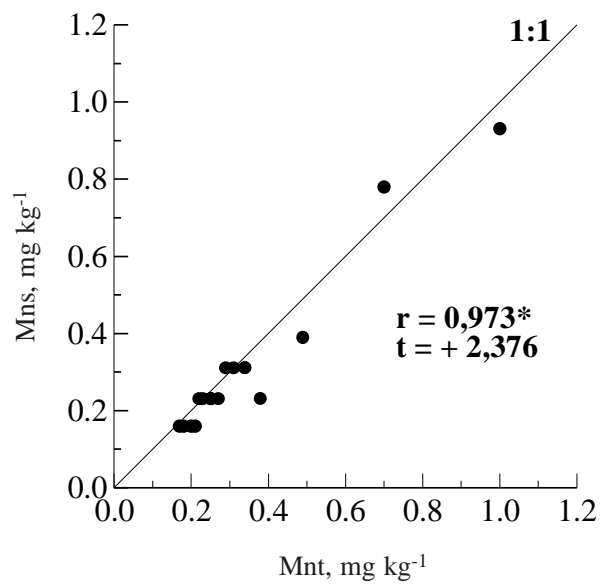

Figura 2. Relação entre os teores de manganês obtidos por ataque sulfúrico $\left(M n_{s}\right)$ e fluorescência de raios-X $\left(M n_{t}\right)$. A reta corresponde a uma inclinação de $45^{\circ}$, passando pela origem.
PERFIL P1

Fed e Fes, $\mathrm{g} \mathrm{kg}^{-1}$

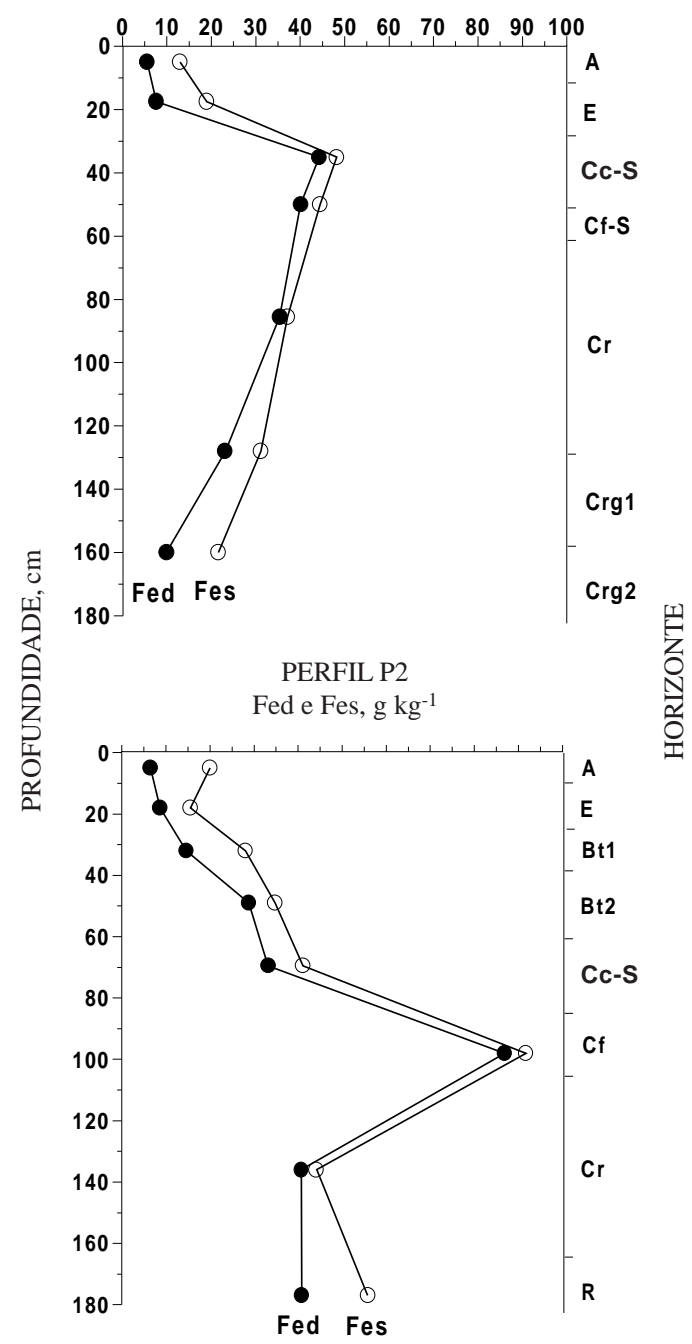

Figura 3. Distribuição, em profundidade, do ferro extraído com ataque sulfúrico $\left(\mathrm{Fe}_{\mathrm{s}}\right)$ e ditionito de sódio $\left(\mathrm{Fe}_{\mathrm{d}}\right.$ ) para os perfis P1 e P2 (nos horizontes nodulares considerou-se apenas sua matriz interglebular).

superficiais, à medida que se aprofunda no perfil (F igura 3), indicando que outras formas, que não hematita egoethita, estão presentes na fração argila e contribuem para o conteúdo de ferro extraído por ataque sulfúrico.

O reagente oxalato-oxálico remove as frações amorfas dos solos e proporciona uma medida da atividade dos componentes (Schwertmann, 1973). Corresponde às frações quimicamente mais ativas dos óxidos e oxiidróxidos (Chao \& Zhou, 1983) e, por isso, influenciam em alguns atributos do sol o (Barral Silva, 1987). Do exame do quadro 4, nota-se que os maiores conteúdos de $\mathrm{Fe}_{\mathrm{o}}$ estão presentes nas glébulas. E mbora este reagente reconheci damente extraia conteúdos significativos de magnetita 
(Rhoton et al.; 1981; Chao \& Zhou, 1983; Lee et al., 1989), pode-se desconsiderar aqui sua contribuição aos valores de $\mathrm{Fe}_{0}$, uma vez que apenas traços do mineral foram identificados em apenas algumas amostras analisadas (Coel ho, 1998).

O maior conteúdo de $\mathrm{Fe}_{0}$ nas glébulas evidencia os diferentes estádios de evolução desses materiais ferruginosos. Nota-se o maior teor nas glébulas plínticas (Cf-N) do perfil P1 (15,12 $\left.\mathrm{g} \mathrm{kg}^{-1}\right)$, evidenciando maiores conteúdos de óxidos de ferro jovens, provenientes da mobilização recente e deposição de $\mathrm{Fe}^{2+}$ durante a formação das plintitas e que não tiveram tempo ou condições adequadas para cristalinizar-se em hematita ou goethita. Por outrolado, os conteúdos também el evados de $\mathrm{Fe}_{0}$ nas glébulas petroplínticas revelam um novo ciclo de formação dos óxidos deferro. Possivelmente, hematita e goethita no interior das glébulas petroplínticas estão se dissolvendo, e uma nova geração de óxidos pouco cristalinos, tal como ferridrita, está sendo formada sob condições mais redutoras. I ssotambém leva à formação de ferro solúvel $\left(\mathrm{Fe}^{2+}\right)$, o qual pode ser redistribuído com uma frente de umedecimento no interior do solo (Schwertmann \& Kämpf, 1983) e acumular-se abaixo, nos poros dos fragmentos saprolíticos e rocha, juntamente com as formas amorfas. As condições adequadas à reoxidação do $\mathrm{Fe}^{2+}$ e recristal inização das formas amorfas nos poros dos fragmentos de saprolito, imediatamente abaixo das glébulas petroplínticas, foram os mecanismos responsáveis pela formação das plintitas, tal comose verifica hoje nos perfis. Evidências macromicromorfológicas e submicroscópicas da degradação atual das petroplintitas, liberando ferro para a formação das plintitas sotopostas, são apresentadas por Coelho (1998) para a área estudada.

A distribuição do ferro ativo $\left(\mathrm{Fe}_{\mathrm{o}} / \mathrm{Fe}_{\mathrm{d}}\right)$ em profundidade é mostrada na figura 4 . Nela, apenas as matrizes interglebulares são consideradas nos horizontes nodulares, com exceção do horizonte plíntico (Cf) do perfil P2, onde as análises foram realizadas homogeneizando-seas gl ébulas ea matriz. Da análise da figura 4, observa-se, para o perfil P1, que os maiores conteúdos de $\mathrm{Fe}_{\mathrm{o}}$ encontram-se na matriz interglebular, reduzindo em profundidade. Esse resultado evidencia tanto a participação de óxidos de ferro jovens oriundos da degradação das glébulas, como a mobilização deste componente nas formas pouco cristalinas e solúvel $\left(\mathrm{Fe}^{2+}\right)$, concentrando-se, inicialmente, na matriz interglebular e, posteriormente, remobilizando-se para os horizontes inferiores.

J untamente com a presença de uma cerosidade forte e abundante, tal como observado em campo e confirmado nas análises micromorfológicas do horizonte $\mathrm{Cr}$ (Coelho et al., 2001), esse maior conteúdo de $\mathrm{Fe}_{\mathrm{o}}$ em relação aos horizontes inferiores pode ser interpretado como proveniente de materiais recentemente depositados (Gamble\& Daniels, 1972),

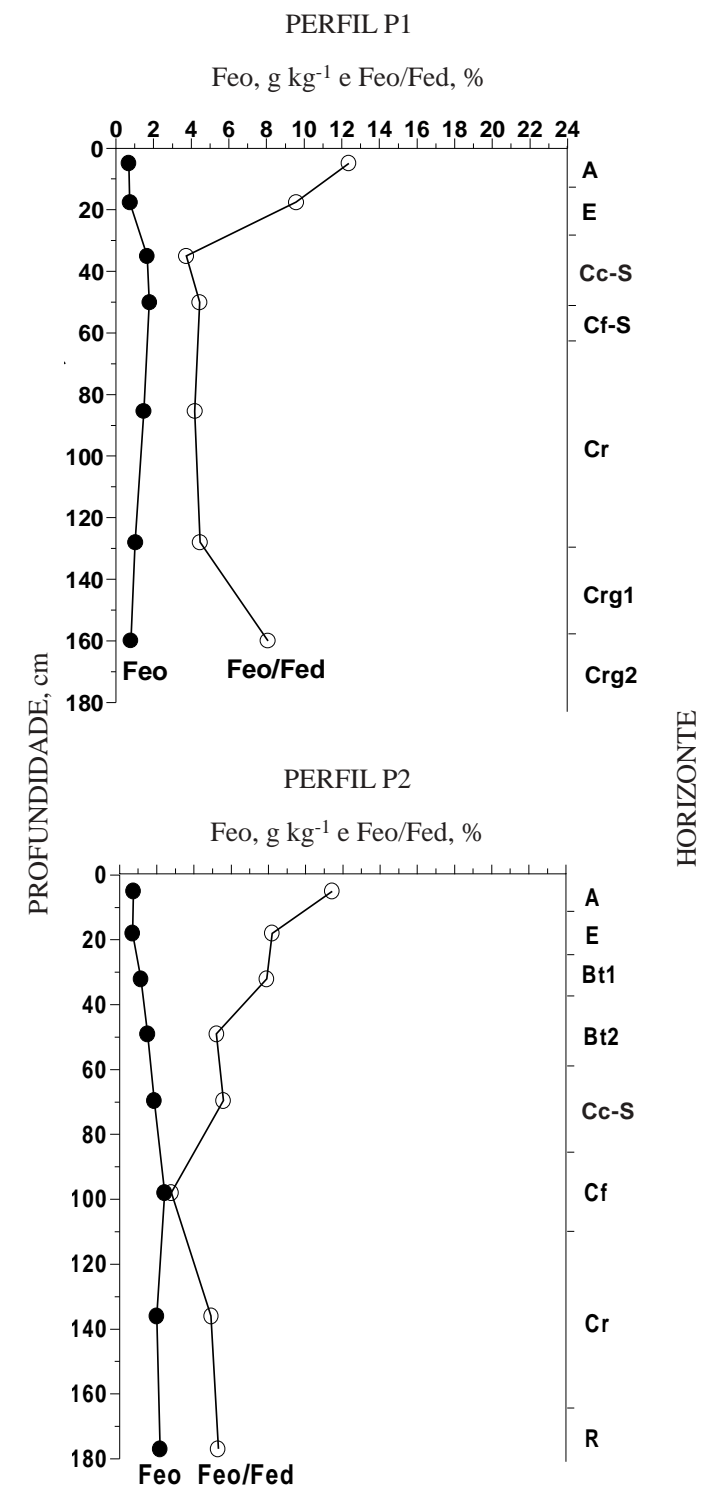

Figura 4. Distribuição, em profundidade, do ferro extraído com oxalato-oxálico $\left(\mathrm{Fe}_{\mathrm{o}}\right)$ e da relação Feo/Fed para os perfis estudados (nos horizontes nodulares considerou-se apenas sua matriz interglebular).

evidenciando mecanismos atuais de remobilizações verticais nos perfis. No entanto, as menores rel ações de ferro ativo encontram-se nas matrizes intergl ebulares, horizontes $\mathrm{Cr}$ eCrgl. Essa relação proporciona uma indicação do conteúdo relativo de compostos de ferro pobremente ordenados ou cristalinos (Blume \& Schwertmann, 1969). Assim, apesar dos maiores teores de $\mathrm{Fe}_{0}$, a relação ferro ativo evidencia que a grande proporção de ferro nesses horizontes está predominantemente na forma cristalina. Essa cristalinidadeéreduzida nos horizontes superficiais A e E e no horizonte Crg2, possivel mente por causa de diferentes fatores. 
Primeiro, para ohorizonte $\mathrm{A}$, seu maior conteúdo de matéria orgânica pode ser responsável pela habilidade de complexar o Fe e estabilizar a ferridrita (a fonte primária de $\mathrm{Fe}_{0}$ ), inibindo, assim, sua transformação para formas mais estáveis de óxidos de ferro (Schwertann \& Taylor, 1989). No entanto, para o horizonte $\mathrm{E}$, a presença de uma maior relação $\mathrm{Fe}_{d} / \mathrm{Fe}_{d}$ pode ser interpretada como conseqüência dos processos envol vidos na eluviação das argilas e gênese do próprio horizonte. Assim, parte do ferro presente neste horizonte (ferro amorfo) é potencial mente capaz de mobilizar-se aos horizontes inferiores ou às porções mais baixas da paisagem, tal como sugerido por Blume \& Schwertmann (1969). Esses autores, referindo-seà mobilidade do ferro, afirmam que as únicas frações móveis nos solos são aquelas solúveis em oxalatooxálico.

Outro fator envolvido no aumento do ferro ativo, agora para o horizonte Crg2 (perfil P2), refere-se à migração descendente de compostos amorfos e de $\mathrm{Fe}^{2+}$, bem como ao lento envel hecimento desses compostos a baixos valores de pH (Blume $\&$ Schwertmann, 1969), tal como pode ser observado neste horizonte (Quadro 2). O ferro solúvel $\left(\mathrm{Fe}^{2+}\right)$, mobilizado dos horizontes petroplínticos superiores, encontra potenciais adequados para sua reoxidação nos horizontes saprolíticos sotopostos, podendo originar compostos pouco cristalinos (ferridrita, por exemplo), dependendo das condições de sua formação, tal como sugerido por Schwertmann \& Kämpf (1983). Assim, as taxas de oxidação lenta (Schwertmann \& Kämpf, 1983), bem como as maiores concentrações de Al (Schwertmann \& Taylor, 1989), são favoráveis à produção de compostos de ferro de baixa cristalinidade e podem ser os principais responsáveis pel os maiores valores de ferro ativo no horizonte Crg2, uma vez que este perfil encontra-se permanentemente saturado na estação chuvosa e apresenta elevados teores de alumínio trocável $\left(38 \mathrm{mmol}_{\mathrm{c}} \mathrm{dm}^{-3}\right)$.

Examinando o perfil P2 (Figura 4 e Quadro 4), nota-se que os teores de $\mathrm{Fe}_{\mathrm{o}}$ aumentam em profundidade, alcançando o máximo valor no horizonte Cfe, a partir daí, mantêm-se praticamente constantes no horizonte $\mathrm{Cr}$ e camada R. Comparativamente ao perfil $\mathrm{P} 1$, os maiores val ores de $\mathrm{Fe}_{0}$ nessas porções inferiores do P2 indicam mobilizações mais significativas de ferro neste perfil, bem como a influência do Al na formação e manutenção deóxidos deferrojovens, pois éna rocha que se encontra o mai or e mais significativo conteúdo de Al trocável $\left(115,5 \mathrm{mmol}_{\mathrm{C}} \mathrm{kg}^{-1}\right)$ dentre todos os horizontes estudados (Quadro 4).

Tal como sugerido por Lepsch et al. (1977), a desestabilização dos agregados e a colocação da argila em suspensão são conseqüências da liberação do ferro dessa argila, promovendo sua eluviação. Portanto, as formas amorfas de ferro dos horizontes
E, Bt1 e Bt2 do perfil P2 podem ser interpretadas como dissociadas das argilas silicatadas e passíveis de mobilidade para os horizontes inferiores desse perfil e, por isso, o ferro ativo é mai or no horizonte $\mathrm{E}$, reduzindo nos horizontes texturais. Isso indica uma maior "disposição" à mobilização do ferro no horizonte $\mathrm{E}$, tal como relatado anteriormente.

Os resultados de ferro extraído com o reagente hidroxilamina $\left(\mathrm{Fe}_{\mathrm{h}}\right)$ são mostrados no quadro 4. Diferentemente dos resultados obtidos por Barral Silva (1987), Chao \& Zhou (1983), Lee et al. (1989) e Ross et al. (1985), as determinações de $\mathrm{Fe}_{\mathrm{h}}$ aqui encontradas foram consi deravel mente inferiores às de $\mathrm{Fe}_{0}$. Esses autores encontraram uma pequena diferença, porém estatisticamentesignificativa entre os diferentes extratores $\left(\mathrm{Fe}_{\mathrm{o}}>\mathrm{Fe}_{\mathrm{h}}\right)$, atribuindo esse resultado à maior seletividade do reagente hidroxilamina, principal mente quando as amostras analisadas apresentavam apreciáveis conteúdos de magnetita. No entanto, essa interpretação não é adequada para o presentetrabal ho pelo insignificante conteúdo desse mineral nos horizontes estudados (Coelho, 1998), pouco contribuindo para os valores do extrato oxalato-oxálico.

Da análise do quadro 4, observa-seque os mai ores conteúdos de $\mathrm{Fe}_{h}$ estão nas glébulas. À semel hança do $\mathrm{Fe}_{0}$, também as plintitas do perfil P1 (F2-C) mostram os maiores teores das formas facilmente redutíveis. Em relação às matrizes interglebulares, horizontes e camadas dos perfis, o maior teor deFe é verificado para a rocha $\left(0,48 \mathrm{~g} \mathrm{~kg}^{-1}\right)$ do perfil P2. Os potenciais de oxirredução eas mobilizações atuais do ferro provenientes da degradação das glébulas petroplínticas são os principais responsáveis pelo maior suprimento de ferro na forma facilmente redutível a essa camada.

Os conteúdos dealumínio ditionito $\left(\mathrm{Al}_{\mathrm{d}}\right)$ e oxalato $\left(\mathrm{Al}_{\mathrm{o}}\right)$ estão representados no quadro 4 e a variação do $\mathrm{Al}_{\mathrm{s}}$ (extraído por ataque sulfúrico), $\mathrm{Al}_{\mathrm{d}}$ e $\mathrm{Al}_{\mathrm{o}} \mathrm{em}$ profundidade, encontra-se na figura 5 . Nota-se que os valores de $\mathrm{Al}_{\mathrm{S}}$ são muito superiores aos do $\mathrm{Al}$ extraído com ditionito-citrato e oxalato-oxálico. Da análise da figura 5 , nota-se que o valor de $\mathrm{Al}_{d}$ foi significativamente superior ao $\mathrm{Al}_{0}$, apenas invertendo essa situação na rocha $(R)$ do perfil P2, além de tais valores estarem muito próximos no horizonte Crg2 do perfil P1 e Cr do perfil P2. O el evado conteúdo de $\mathrm{Al}_{0}$ presente na rocha e a sua proximidade aos valores de $\mathrm{Al}_{d}$ devem estar relacionados com o maior conteúdo de minerais silicatados de baixa cristalinidade (principalmente caulinita), tal como sugerido por McK eague \& Day (1966). Esses autores encontraram que muito mais Al foi removido pel o extrator oxalato-oxálico que por DC para materiais AI-Si amorfos, embora Partiff \& Childs (1988) tenham demonstrado que o oxalato não dissolveu aluminossilicatos. Supostamente, os solos utilizados por esses últimos autores não continham el evados conteúdos de constituintes 
silicatados amorfos. Barral Silva (1987) também argumenta que a extração do alumínio com oxalato pode provocar a solubilização do Al interlaminar dos filossilicatos. Aqui, pode-se considerar a ferrólise como prinipal responsável por desestabilizar a estrutura da caulinita. Esse fato, associado ao intemperismo dos minerais primários, principalmente feldspatos, e à mobilização de silício provindo da degradação das glébulas, contribui para a formação de compostos silicatados de baixa cristalinidade, e esses, para os elevados teores de $\mathrm{Al}_{0}$. Portanto, o reagente oxalato-oxálicoé, supostamente, o extrator mais efetivo das formas amorfas de alumínio.

PERFIL P1

Als, Ald e Alo, $\mathrm{g} \mathrm{kg}^{-1}$

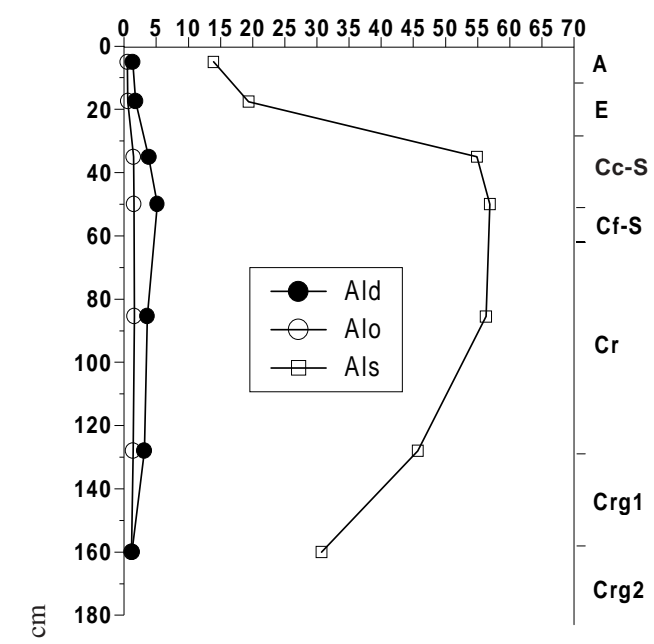

PERFIL P2

Als, Ald e Alo, $\mathrm{g} \mathrm{kg}^{-1}$

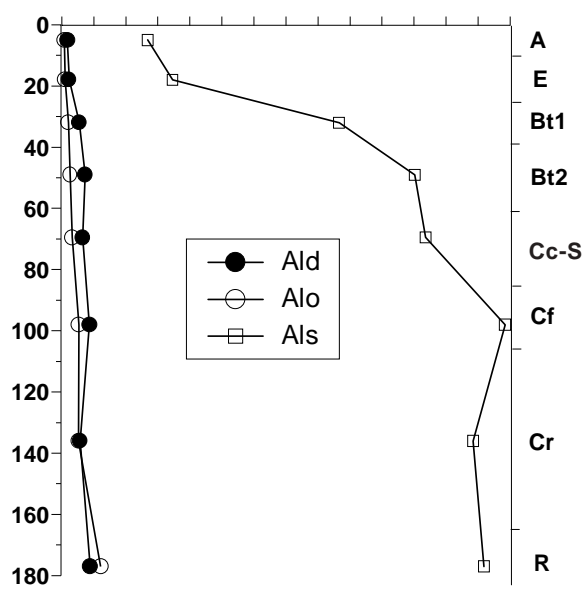

Figura 5. Distribuição, em profundidade, do alumínio extraído por ataque sulfúrico $\left(\mathrm{Al}_{\mathrm{s}}\right)$, ditionito de sódio $\left(\mathrm{Al}_{\mathrm{d}}\right)$ e oxalato-oxálico $\left(\mathrm{Al}_{\mathrm{o}}\right)$ (nos horizontes nodulares considerou-se apenas sua matriz interglebular).
Embora o extrator DC remova parte do Al da gibbsita (Buurman et al. 1996), as condições atuais são inadequadas à formação deste mineral devido ao elevado conteúdo de silício (Anjos et al., 1995) presente nas amostras, o que é evidenciado pela completa ausência ou presença apenas de pequenas proporções do mineral, identificada nas análises mineralógicas e submicroscópicas dos perfis analisados (Coel ho \& Vidal-Torrado, 2003). Assim, o Al dissolvido no ditionito-citrato provavelmente provém da substituição isomórfica do Fe por Al na estrutura da hematita e goethita (Shadfan et al., 1985; Barral Silva, 1987; Partiff \& Childs, 1988). Barral Silva et al. (1988) consideram que a ordem de extratibilidade, $\mathrm{Al}_{\mathrm{d}}>\mathrm{Al}_{\mathrm{O}}$, tem de ser atribuída às substituições aluminosas nas formas cristalinas de ferro, fato comprovado nestas amostras por difratometria de raios-X (Coelho $\&$ Vidal Torrado, 2003). Pela análise da relação $A I_{d} / F_{d}$ (Quadro 4), os óxidos e oxiidróxidos de ferro presentes nas glébulas são pouco aluminosos. Essa relação fornece uma indicação da quantidade de Al presente nos óxidos de ferro, uma vez que o extrator DC remove principalmente essas formas do solo. Maiores detalhes são apresentados por Coelho \& VidalTorrado (2003) por meio de análises mineralógicas, visto que, em se tratando de amostras que contenham tanto hematita como goethita, tais como constatado para os perfis estudados (Coelho \& VidalTorrado, 2003), esses valores de dissol uções sel etivas para avaliar o grau de substituição por al umínio nos óxidos de ferro mostram-se muito variáveis (Shadfan et al., 1985).

Os conteúdos de manganês extraídos com DC $\left(M n_{d}\right)$, oxalato-oxálico $\left(M n_{o}\right)$ e hidroxilamina $\left(M n_{h}\right)$ são mostrados na quadro 4. Analisando as diferentes formas do elemento nas glébulas, nota-se que os maiores val ores correspondem aos observados na sua forma cristalina, identificados como $\mathrm{Mn}_{\mathrm{d}}$. Teores similares são encontrados para as diferentes glébulas nos perfis. No entanto, há uma variação considerável nos conteúdos de $\mathrm{Mn}_{0}$, apesar de essa forma encontrar-se em pequenas proporções em relação ao $M n_{d}$. Por analogia ao ferro solúvel em oxalato-oxálico, o manganês extraído com esse reagente pode ser considerado como amorfo (Barral Silva et al., 1988). Sendo assim, maiores conteúdos amorfos do el emento estão presentes nas glébulas plínticas do perfil P1 (Cf-N).

Tal comosugerido para os compostos de ferro, as recentes deposições e formação dessas feições são responsáveis pela baixa cristal inidade dos compostos manganíferos. Essas variações entre as plintitas e petroplintitas são menos significativas para o extrator hidroxilamina, que mostram resultados superiores em relação ao oxalato-oxálico para a maioria das amostras analisadas.

Dentre os perfis analisados, os mai ores conteúdos de manganês são observados no perfil P2. Como 
comentado anteriormente, o elemento mobilizado das porções a montante do perfil encontra potenciais de oxirredução adequados no horizonte $\mathrm{Cr}$ e camada R do P2, originando películas enegrecidas na superfície dos fragmentos saprolíticos, tal como observados em campo. No entanto, nota-se que as formas facilmente redutíveis $\left(M n_{h}\right)$ são consideravelmente superiores às cristalinas $\left(\mathrm{Mn}_{\mathrm{d}}\right)$ e amorfas $\left(\mathrm{Mn}_{\mathrm{o}}\right)$, sugerindo que o el emento está pouco cristalinizado e móvel. Portanto, ou foram recentemente depositados e ainda não tiveram tempo para cristalizar-se, ou as condições de Eh e $\mathrm{pH}$ não possibilitam sua cristalização. O certoé que a capacidade redutora do extrator hidroxilamina sobrepôs-se ao efeito complexante e redutor dos reagentes ditionito-citrato e oxalato-oxálico, removendo maiores conteúdos de $\mathrm{Mn}$ de baixa cristalinidade.

Teores similares entre os três extratores são observados desde o horizonte $\mathrm{A}$ até o horizonte Cf$\mathrm{N}$, revelando formas pouco cristalinas de manganês por todo o perfil P2; fato que, associado aos maiores teores do el emento nas formas oxalato-oxálico e facilmente redutíveis, evidencia as maiores mobilizações de elementos neste perfil em relação ao perfil $\mathrm{P} 1$, tal como relatado para o ferro.

Os resultados de dissol uções sel etivas evidenciam as transferências de matéria durante a evolução dos perfis, bem como a influência da degradação das glébulas petroplínticas na sua matriz friável e nos horizontes e camada sotopostos, originando as plintitas mais macias e com menores conteúdos de ferro cristalino e maiores teores de materiais amorfos, comparativamente às petroplintitas.

\section{CONCLUSÕES}

1. As glébulas petroplínticas apresentaram os maiores conteúdos de ferro total no perfil $\left(\approx 300 \mathrm{~g} \mathrm{~kg}^{-1}\right)$, seguidas pelas plínticas $\left(\approx 160 \mathrm{~g} \mathrm{~kg}^{-1}\right)$. Enquantoas primeiras são compostas essencialmente por óxidos e oxiidróxidos de ferro cristalinos, as plintitas apresentam os maiores teores dos compostos de ferro de baixa cristalinidade dentre todas as amostras analisadas.

2. As petroplintitas apresentaram os menores valores de silício total e $\mathrm{Ki}$, bem como os maiores teores de $\mathrm{Fe}_{\mathrm{d}}$ dentre todas as amostras analisadas, evidenciando sua constituição predominantemente oxídica.

3. Os resultados evidenciam a origem poligenética dos perfis estudados. Processos de segregação e precipitação do ferro em massa, mecanismos de ferrólise e de iluviação de compostos de ferro, degradação dos horizontes petroplínticos, liberando ferro para a gênese das plintitas sotopostas, aparentam ser os principais mecanismos pedogenéticos atuantes nos perfis estudados, influenciando sobremaneira os atributos químicos dos horizontes saprolíticos.

\section{LITERATURA CITADA}

ALEXANDER, T.L. \& CADY, J.G. Genesis and hardening of laterite in soils. Washington, D.C., Soil Conservation Service, United States Department of Agriculture, 1962. 90p. (Technical Bulletin, n.1282).

ANJ OS, L.H.C.; FRANZMEIER, D.P. \& SCHULZE, D.G. Formation of soils with plinthite on a toposequence in Maranhão State, Brazil. Geoderma, 64:257-279, 1995.

BARRAL SILVA, M.T. Estudio de las separaciones de hierro y manganeso en suelos y sedimentos de Galicia. Santiago, Facultad de Biología de la Universidad de Santiago de Compostela, 1987. 680p. (Tese de Doutorado)

BARRAL SILVA, M.T.; TABOADA CASTRO, M.T. \& GUITIAN OJ EA, F. Caracterización quimica y mineralogica de las formas de hierro en suel os sobre substrato calizo de Galicia (nw de España). An. Edafol. Agrobiol., 48:1303-1321, 1988.

BLUME, H.P. \& SCHWERTMANN, U. Genetic evaluation of distribuition of aluminium, iron, and manganese oxides. Soil Sc. Soc. Am. Proc., 33:438-444, 1969.

BOURMAN, R.P. Modes of ferricrete genesis: evidence from southeastern Australia. Z. Geomorphol., 37:77-101, 1993.

BRINKMAN, R. Ferrolysis, a hydromorphic soil forming process. Geoderma, 3:199-206, 1970.

BUURMAN, P.; LAGEN, B. \& VELTHORST; E.J . Manual for soil and water analysis. Wageningen, Backhuys Publihers Leiden, 1996. 314p.

CHAO, T.T. \& ZHOU, L. Extraction techniques for selective dissolution of amorphous iron oxides from soils and sediments. Soil Sci. Soc. Am. J ., 47:225-232, 1983.

COELHO, M.R. Caracterização e gênese de ferricretes desenvolvidos do arenito Bauru, Formação Adamantina (Ka), no município de Pindorama (SP). Piracicaba, Escola Superior de Agricultura "Luiz de Queiroz", 1998. 233p. (Tese de Mestrado)

COELHO, M.R. \& VIDAL-TORRADO, P. Caracterização e gênese de perfis plínticos desenvolvidos de arenito do Grupo Bauru. II - Mineralogia. R. Bras. Ci. Solo, 27:495-507, 2003.

COELHO, M.R.; VIDAL-TORRADO, P. \& LADEIRA, F.S.B. Macro e micromorfologia de ferricretes nodulares desenvolvidos de arenito do Grupo Bauru, Formação Adamantina. R. Bras. Ci. Solo, 25:371-385, 2001.

EMPRESA BRASILEIRA DE PESQUISA AGROPECUÁRIA EMBRAPA. Centro Nacional de Pesquisa de Solos. Sistema Brasileiro de Classificação de Solos. Rio de J aneiro, 1999. 412p.

GAMBLE, E.E. \& DANIELS, R.B. I ron and silica in water, acid ammonium oxalate, and dithionite extracts of some N orth Carolina coastal plain soils. Soil Sci. Soc. Am. Proc., 36:939943, 1972. 
GAMBRELL, R.P. Manganese. In: SPARKS, D.L.; PAGE, A.L.; HELMKE, P.A.; LOEPPERT, R.H.; SOLTANPOUR, P.N.; TABATABAI, M.A.; J OHNSTON, C.T. \& SUMNER, M.E., eds. Methods of soil analysis. Chemical methods. Madison, Soil Science Society of America, 1996. Part 3. p.665-682. (Book Series, 5)

IBANGA, I.J . The physical, chemical, and mineralogical properties of laterite samples formed in various environments. Raleigh, University of Raleigh, 1980. 120p. (Tese de Doutorado)

INSTITUTO DE PESQUISAS TECNOLÓGICAS DO ESTADO DE SÃO PAULO - IPT. Mapa Geológico do estado de São Paulo. Escala 1:500.000. São Paulo, IPT, 1981. v.1. 126p.

LEE, R.; TAYLOR, M.D. \& DALY, B.K. The extraction of AI, Fe and $\mathrm{Si}$ from a range of $\mathrm{New}$ Zealand soils by hydroxylamine and ammonium oxalate solutions. Aust. J . Soil Res., 27:377388, 1989.

LEPSCH, I.F.; BUOL, S.W. \& DANIELS, R.B. Soil landscape relationships in the Occidental Plateau of São Paulo State, Brazil: Part II. Soil morphology, genesis and classification. Soil Sci. Soc. Am. J ., 41:109-115, 1977.

MCKEAGUE, J.A. \& DAY, J.H. Dithionite-and oxalateextractable $\mathrm{Fe}$ and $\mathrm{Al}$ as aids in differentiating various classes of soils. Can. J . Soil Sci., 46:13-22, 1966.

MCKENZIE, R.M. Manganese Oxides and Hydroxides. In: DIXON, J.B. \& WEED, S.B., eds. Mineral in soil environments. 2 ed. Madison, Soil Science Society of America, 1989. p.439-461.

PARTIFF, R.L. \& CHILDS, C.W. Estimation of forms of Fe and Al: a review, and analysis of contrasting soils by dissolution and Moessbauer methods. Aust. J . Soil Res., 26:121-144, 1988.

RAIJ , B. van \& VALADARES, J .M.A.S. Análise dos elementos maiores de rochas, argilas e solos. Campinas, Instituto Agronômico de Campinas, 1974. 23p. (IAC. Boletim Técnico, 16)

RAIJ , B. van; QUAGGIO, J .A.; CANTARELLA, H.; FERREIRA, M.E.; LOPES, A.S. \& BATAGLIA, O.C. Análise química do sol o para fins defertilidade. Campinas, Fundação Cargill, 1987. 170p.
RHOTON, F.E.; BIGHAM, J .M. \& NORTON, L.D. Contribuition of magnetite to oxalate-extractable iron in soils and sediments from the Maumee river basin of Ohio. Soil Sci. Soc. Am. J ., 45:645-649, 1981.

ROQUIN, C.; PAQUET, H.; FREYSSINET, P.; BOEGLIN, J .L. \& TARDY, Y. Lithodependence and homogeization of mineralogical and chemical composition of ferricretes. Chem. Geol., 84:124-137, 1990.

ROSS, G.J .; WANG, C. \& SCHUPPLI, PA. Hydroxylamine and ammonium oxalate solutions as extractants for iron and aluminium from soils. Soil Sci. Soc. Am. J ., 49:783-785, 1985.

SCHWERTMANN, U. Use of oxalate for Fe extraction from soils. Can. J . Soil Sci., 53:244-246, 1973.

SCHWERTMANN, U. \& KÄMPF, N. Óxidos de ferro jovens em ambientes pedogenéticos brasileiros. R. Bras. Ci. Solo, 7:251-255, 1983.

SCHWERTMANN, U. \& TAYLOR, R.M. I ron oxides. In: DIXON, J .B. \& WEED, S.B., eds. Mineral in soil environments. 2.ed. Madison, Soil Science Society of America, 1989. p.380-427.

SHADFAN, H.; DIXON, J.B. \& CALHOUN, F.G. Iron oxide properties versus strength of ferruginous crust and ironglaebules in soils. Soil Sci., 140:317-325, 1985.

SIVARAJ ASINGHAM, S.; ALEXANDER, L.T.; CADY, J .G. \& CLINE, M.G. Laterite. Adv. Agron., 14:1-60, 1962.

SOARES, P.C.; LANDIM, P.M.B.; FÚLFARO, V.J . \& NETO SOBREIRO, A.F. Ensaio de caracterização estratigráfica do cretáceo no estado de São Paulo: Grupo Bauru. R. Bras. Geoc., 10:177-235, 1980.

TARDY, Y. Pétrologie des latérites et des sols tropicaux. Paris, Masson, 1993. 459p.

TAYLOR, R.M. \& MCKENZIE, R.M. The association of trace elements with manganese minerals in Australian soils. Aust. J . Soil Res., 2:235-248, 1966.

VETTORI, L. Métodos de análise de solos. Rio de J aneiro, Ministério da Agricultura, 1969. 24p. (Boletim técnico, 7) 